\title{
CORRECTION
}

\section{Correction to: Potential of solar energy in Iran for carbon dioxide mitigation}

\author{
A. Shahsavari ${ }^{1} \cdot$ F. Tabatabaei Yazdi ${ }^{1} \cdot$ H. Tabatabaei Yazdi ${ }^{2}$
}

Published online: 17 July 2018

(C) Islamic Azad University (IAU) 2018

\section{Correction to: International Journal of Environmental Science and Technology \\ https://doi.org/10.1007/s13762-018-1779-7}

The original version of this article unfortunately contained a mistake.

The family name of the second and third authors was incorrect. The corrected names are given above.

The original article can be found online at https://doi.org/10.1007/ s13762-018-1779-7.

A. Shahsavari

amir.shahsavari@mail.um.ac.ir

1 Faculty of Natural Resources and Environment, Ferdowsi University of Mashhad, Mashhad, Iran

2 Faculty of Engineering, Ferdowsi University of Mashhad, Mashhad, Iran 